\title{
A Low-Erosion Starting Technique for High-Performance Arcjets
}

John M. Sankovic and Francis M. Curran

Lewis Research Center

Cleveland, Ohio

Prepared for the

30th Joint Propulsion Conference

cosponsored by AIAA, ASME, SAE, and ASEE

Indianapolis, Indiana, June 27-29, 1994

National Aeronautics and

Space Administration 


\title{
A LOW-EROSION STARTING TECHNIQUE FOR HIGH-PERFORMANCE ARCJETS
}

\author{
John M. Sankovic* and Francis M. Curran * \\ National Aeronautics and Space Administration \\ Lewis Research Center \\ Cleveland, $\mathrm{OH} 44135$
}

\begin{abstract}
The NASA arcjet program is currently sponsoring development of high specific impulse thrusters for next generation geosynchronous communications satellites ( $2 \mathrm{~kW}$-class) and lowpower arcjets for power limited spacecraft ( 0.5 kW-class). Performance goals in both of these efforts will require up to 1000 starts at propellant mass flow rates significantly below those used in state-of-art arcjet thruster systems (i.e. high specific power levels). Reductions in mass flow rate can lead to damaging modes of operation, particularly at thruster ignition. During the starting sequence, the gas dynamic force due to low propellant flow is often insufficient to rapidly push the arc anode attachment to its steady-state position in the diverging section of the nozzle. This paper describes the development and demonstration of a technique which provides for non-damaging starts at low steady-state flow rates. The technique employs a brief propellant pressure pulse at ignition to increase gas dynamic forces during the critical ignition/transition phase of operation. Starting characteristics obtained using both pressurepulsed and conventional starting techniques were compared across a wide range of propellant flow rates. The pressure-pulsed starting technique provided reliable starts at mass flow rates down to $21 \mathrm{mg} / \mathrm{s}$, typically required for $700 \mathrm{~s}$ specific impulse level operation of $2 \mathrm{~kW}$ thrusters. Following the comparison, a 600 start test was performed across a wide flow rate range. Posttest inspection showed minimal erosion of critical arcjet anodelnozzle surfaces.
\end{abstract}

\section{INTRODUCTION}

Joint NASA/industrial arcjet development efforts of the 1980's resulted in a flightqualified $1.8 \mathrm{~kW}, 500 \mathrm{~s}$ nominal mission average (NMA) specific impulse ( $I_{S p}$ ) hydrazine arcjet system.1,2 These first generation arcjet systems have been accepted for north-south stationkeeping on several geosynchronous commercial communications satellite series and have attained operational status aboard the recently-launched Telstar 401 spacecraft. In 1991, NASA initiated the Arcjet Technology Development Program. Major goals of this program are to demonstrate qualification-life of a $2 \mathrm{~kW}, 600 \mathrm{~s}$ NMA Isp arcjet and to determine the ultimate performance limit of $2 \mathrm{~kW}$-class arcjet thrusters operating on hydrazine. To date, the program has demonstrated that extended life at performance levels above $600 \mathrm{~s}$ specific impulse is achievable, ${ }^{3}$ and a $1000 \mathrm{~h} / 1000$ cycle system demonstration of a second generation, $600 \mathrm{~s}$ thruster is currently underway.

One of the major life-limiting problems of high-performance arcjets is start-up erosion of the anode. To start the arcjet, state-ofart (SOA) systems first initiate operational propellant flow. Once the flow rate is stablized, a $3-4 \mathrm{kV}$ voltage pulse is applied to break down the gas to a voltage level below the open circuit voltage of the main discharge power supply.4-6 Arc ignition occurs between the cathode and the upstream (converging) side of the anode/nozzle in the high-pressure, subsonic region of the arcjet. 5 This

\footnotetext{
*Aerospace Engineer, On-Board Propulsion Branch, Member AIAA

${ }^{* *}$ Senior Research Scientist, On-Board Propulsion Branch, Member AIAA
} 
condition is termed low-mode in reference to the low operating voltage typically observed. In this mode the anode attachment is highly localized, resulting in high, potentially damaging, heat loads on the anode. To provide reliable, nondamaging starts, gas dynamic forces produced by the propellant flow field must rapidly push the arc anode attachment through the throat and into the supersonic region. This is the steady-state condition commonly referred to as high-mode operation. To increase specific impulse, the specific power at which the arcjet is operated must be increased, typically by lowing mass flow rates. As mass flow rate is decreased, the gas dynamic forces responsible for transition to high mode operation are reduced, until reliable starting is no longer possible. Hamley and Sankovic ${ }^{7}$ demonstrated a starting technique incorporating a soft-start current profile which reduced starting damage at low flow rates compared to the SOA method. In that study the arcjet was started at a current level substantially below the steady-state current, in order to reduce the anode heat load during the period spent in low-mode. The current was then ramped to the steady-state value after high-mode operation was attained. Electrode damage was negligible at flow rates corresponding to a specific impulse level of $620 \mathrm{~s}$. The technique was not effective at very low mass flow rates, and an alternate technique is required.

The technique described in this paper utilizes a gas pulse initiated immediately prior to application of a high-voltage pulse train. The pressure pulse increases the gas dynamic forces on the arc during the starting sequence to accommodate rapid transition to high-mode operation. The new technique can be used separately or in tandem with the soft-start ignition circuitry developed in the earlier study. In the first series of tests reported herein, ignition tests were conducted both with and without the use of the pressure pulse to determine the benefits of the technique in reducing arc duration in the converging section of the nozzle. The second phase of testing consisted of a multistart test at progressively decreasing flow rates. A total of 600 starts were performed, and comparisions of anode erosion are made with soft-start technology.

\section{EXPERIMENTAL APPARATUS}

\section{THRUSTER}

Two arcjet thruster assemblies were used in the course of testing. For the first set of tests used to validate the pressure-pulse starting concept, a modular, low-power design with a long history of previous testing was used.8 A schematic of the thruster (Thruster A) is shown in Figure 1a. To improve the reliability of the laboratory thruster, the design was modified to minimize the number of sealed joints. A schematic of this thruster, (Thruster B), is shown in Figure 1b. A similar design has been used successfully for high-power, hydrogen arcjet performance testing. ${ }^{9}$ In this design, the boron nitride rear section was replaced with a stainless steel structure incorporating a small, commercially-available, ceramic insulator to provide electrical isolation from the cathode. The insulator was brazed to metal stand-offs which were then electronbeam welded to form the rear assembly. The propellant tube seal was eliminated by welding the propellant delivery tube to the rear structure. The seals between the anode and the housing and between the injection disk and the anode were lapped metal-tometal joints. Several features of the old design were retained, including the Inconel spring to compensate for thermal expansion, and a compression-type fitting to set the arc gap. Two different nozzle geometries were used and are shown in Figure 1c. The nozzles differed only in constrictor diameter. The constrictor diameter in the Thruster A nozzle was $0.064 \mathrm{~cm}$ and while the constrictor diameter used in Thruster B was $0.046 \mathrm{~cm}$. Both nozzles were made from $2 \% \mathrm{ThO}_{2} / \mathrm{W}$ and had conical converging and diverging sections with $30^{\circ}$ and $20^{\circ}$ half angles, respectively. The constrictor length was $0.025 \mathrm{~cm}$ and the exit diameter 
was $0.95 \mathrm{~cm}$ in both cases. The cathodes were fabricated from $0.32 \mathrm{~cm}$ diameter rods of $2 \% \mathrm{ThO}_{2} / \mathrm{W}$ which were machined to a conical tip with a $30^{\circ}$ half angle. A gas injector disk with two $0.038 \mathrm{~cm}$ diameter tangential holes provided a vortex in the flow.

\section{POWER PROCESSOR}

The design for the power processor unit (PPU) used was described by Gruber. ${ }^{4}$ It is based on a pulse-width-modulated power converter which was configured with a fast, closed-loop current control. The maximum output current of the device was $15 \mathrm{~A}$ and the open circuit voltage was limited to $200 \mathrm{~V}$. A high-voltage $(4 \mathrm{kV})$ pulse train with variable frequency was provided for arc ignition.

\section{FACILITY}

The facility used was an vacuum chamber designed for autonomous endurance testing. ${ }^{1}$ The chamber consisted of a bell jar $0.5 \mathrm{~m}$ in diameter by $0.6 \mathrm{~m}$ in height and is pumped by a single, oil-sealed, rotary pump. Pressure in the facility was below $100 \mathrm{~Pa}$ for all testing described herein. A schematic of the apparatus used to generate the pressure pulse is shown in Figure 2. This apparatus was mounted outside the vacuum facilty and consisted of two propellant isolation valves and an accumulator. A programmable logic controller was configured to operate the facility, propellant isolation valves, and the power processing unit for cyclic operation.

\section{EXPERIMENTAL PROCEDURE}

The propellant used during all testing was a 2:1 gaseous mixture of hydrogen and nitrogen used to simulate the decomposition products of hydrazine. As noted above, the system used to generate the pressure pulse consisted of two valves and an accumulator. To charge the accumulator, the thruster isolation valve, $V_{t}$, was closed and the accumulator isolation valve, $\mathrm{V}_{\mathrm{a}}$, was opened, allowing the pressure in the accumulator to reach the propellant feed pressure. Once charged, the accumulator was isolated by closing $\mathrm{V}_{\mathrm{a}}$ and normal propellant flow to the arcjet was initiated by opening $V_{t}$. To start the arcjet, the propellant in the accumulator was released by opening $\mathrm{V}_{\mathrm{a}}$, causing a step change in the arcjet chamber and high-voltage pulses were sent from the PPU to ignite the discharge. In a typical starting sequence several pulses were required for starting.

The steady-state current level was set at 10 A for two reasons. First, since this was a test to investigate start-up erosion, it desirable to eliminate steady-state effects caused by high current operation. Second, it was assumed that, in practice, the power processor would be designed to ramp-up the current after ignition 7 , and that current levels greater than $10 \mathrm{~A}$ would not be encountered until high-mode operation was achieved.

Testing was performed in two segments. The objective of the first segment was to investigate whether the use of a pressure pulse to increase the gas dynamic drag force on the arc during ignition was effective in reducing the time spent in the converging section of the anode. For this set of tests Thruster A was used. The nozzle geometry for these tests was similar to those used in first generation arcjets.

For this set of tests the thruster was started both with and without the pressure-pulse technique at flow rates of $45 \mathrm{mg} / \mathrm{s}, 33 \mathrm{mg} / \mathrm{s}$, and $21 \mathrm{mg} / \mathrm{s}$. The first two flow rates represented the limits typically encountered in the operation of SOA ( $500 \mathrm{~s}$ Isp) arcjet systems. The third flow rate was estimated to be that required to obtain a specific impulse level of $700 \mathrm{~s}$. Prior to the first test segment, the arc gap was set to $0.064 \mathrm{~cm}$.

The goal of the second test segment was to determine the degradation of the anode after a series of multistart tests at various flow rates, as shown in Figure 3. The test conditions were chosen to match those used 
in the soft-start circuit multistart test. ${ }^{7}$ Five blocks of 100 starts each at decreasing flow rates of $45,41,37,33$, and $30 \mathrm{mg} / \mathrm{s}$ were originally planned to represent the blowdown requirements for a second generation arcjet with a $600 \mathrm{~s}$ NMA specific impulse. After completion of the first 500 starts with the pressure-pulse technique, the degradation of the anode was minimal, and an additional block of 100 starts at 25 $\mathrm{mg} / \mathrm{s}$ was added to the test segment.

The testing was fully automated and operated by a programmable logic controller. The controller operated the propellant valves along with the PPU. Each operating cycle was 15 minutes long and included 5 minutes of thruster operation. The remaining 10 minutes allowed for arcjet cooling and charging of the accumulator.

To provide greater hermetic integrity, Thruster B was used in this test segment. The smaller constrictor diameter increased the stability of low-flow operation and matched the configuration used in the softstart study. The thruster was disassembled after each test block to examine the erosion of the electrodes. To investigate the effects on the cathode, a newly tipped cathode was used for each assembly, and the arc gap was set to $0.058 \pm 0.003 \mathrm{~cm}$.

\section{RESULTS AND DISCUSSION}

TEST SEGMENT A CONCEPT EVALUATION

The goal in all supersonic-anodeattachment arcjet starting techniques is to minimize the duration the arc spends in the converging section. Previous arcjet performance testing, including the use of segmented anodes, 10 has shown that the arc voltage can be used as a diagnostic for predicting the location of the arc in the nozzle. For nitrogen/hydrogen mixtures representing decomposed hydrazine, arc voltage below $50 \mathrm{~V}$ is considered low-mode operation, where the arc attachment point is contained in the high-pressure, subsonic region of the nozzle. This highly erosive mode is characterized by the lack of a visible plume and often the expulsion of molten electrode material.

Typically, during the first several highvoltage pulses the pressure would be too high for a breakdown to occur. Then, the next group of pulses would begin to break down the gas, but the arc voltage would be above the PPU open circuit voltage and the main discharge would not ignite due to the elevated pressure. Finally, as the pressure continued to decrease with time, the arc voltage after breakdown would be below the PPU open circuit voltage and the main discharge would be initiated. Having a pulsing circuit with high repetition capability, allowed start-up at the highest possible pressures, since the pressure drop between high-voltage pulses was small.

Figure 4 shows oscilloscope traces of the voltage and current demonstrating the effectiveness of the pressure pulse technique. The current set point was $10 \mathrm{~A}$ and the initial deviation from that point during start-up was due to current control circuitry. ${ }^{7}$ For the SOA technique, even at the highest flow rate of $45 \mathrm{mg} / \mathrm{s}$, low-mode operation was apparent. As shown in Figure $4 \mathrm{a}$, the length of time spent below 50 $\mathrm{V}$ was under $10 \mathrm{~ms}$. After that time period the thruster entered high-mode, and the voltage steadily increased until the steady-state level was reached. At $40 \mathrm{~ms}$ the voltage was $60 \mathrm{~V}$ and rising. The same starting sequence was performed using the pressure-pulse technique. The resulting voltage and current traces are shown in Figure $4 \mathrm{~b}$. For these cases the voltage trace was much different. The voltage after ignition never dropped below $50 \mathrm{~V}$ for an appreciable time period and reached $90 \mathrm{~V}$ within $2 \mathrm{~ms}$. Except for an excursion at $5 \mathrm{~ms}$ the voltage was higher than the steadystate value and then decreased to that level. When the pressure pulse was released, the mass flow rate increased, raising the arc impedance. As the flow rate 
reached the steady-state value, the voltage correspondingly decreased.

The benefit of using the pressure-pulse technique became more apparent at flow rates below $33 \mathrm{mg} / \mathrm{s}$. Figure $4 \mathrm{c}$ shows a typical SOA start at $33 \mathrm{mg} / \mathrm{s}$. In this case the voltage remained below $50 \mathrm{~V}$ for over 20 ms. Using the pressure-pulse technique, the voltage was above $80 \mathrm{~V}$ within $1 \mathrm{~ms}$ of ignition as shown in Figure 4d. Similar to the $45 \mathrm{mg} / \mathrm{s}$ case, a brief excursion to $50 \mathrm{~V}$ was noted about $5 \mathrm{~ms}$ after ignition, but the voltage rapidly returned to $80 \mathrm{~V}$.

Figure $4 \mathrm{e}$ shows the voltage trace obtained using the SOA at $21 \mathrm{mg} / \mathrm{s}$, the lowest flow rate tested. The trace shows that the thruster remained in low-mode indefinately under these conditions. The voltage remained at $30 \mathrm{~V}$ even after $40 \mathrm{~ms}$. Visual observations of the thruster showed metal being expelled. In comparison the pressure-pulse technique gave dramatically improved results, as shown in Figure 4f. Within $1 \mathrm{~ms}$ after ignition the voltage was at $100 \mathrm{~V}$, and the thruster was operating in a steady-state mode. Thus, the pressure-pulse technique demonstrated the ability to decrease damaging lowmode operation across a wide range of propellant flow rates, and the second test segment was initiated.

\section{TEST SEGMENT B -}

\section{MULTISTART TESTING}

The testing in this segment was conducted in blocks of 100 starts each at flow rates beginning at $45 \mathrm{mg} / \mathrm{s}$ and decreasing to 25 $\mathrm{mg} / \mathrm{s}$ as shown in Figure 3. Oscilloscope traces of the current and voltage immediately after ignition are provided in Figure 5. The graphs show representative starts at $45 \mathrm{mg} / \mathrm{s}, 33 \mathrm{mg} / \mathrm{s}$ and $25 \mathrm{mg} / \mathrm{s}$ at two time scales which include events up to $3 \mathrm{~ms}$ and $40 \mathrm{~ms}$ after ignition. The figure shows that the starts $25 \mathrm{mg} / \mathrm{s}$ are as good, or better, than those obtained at the higher flow rates. Figure $5 \mathrm{f}$ shows that even at the lowest flow rate of $25 \mathrm{mg} / \mathrm{s}$, the thruster reached high-mode within $0.5 \mathrm{~ms}$ after breakdown.
The original intention of the multistart test was to compare the results to those obtained using the soft-start technique. ${ }^{7}$ In that test the arcjet was subjected to 500 starts in blocks of 100 at flow rates ranging from $45 \mathrm{mg} / \mathrm{s}$ to $30 \mathrm{mg} / \mathrm{s}$. The soft-start technique provided satisfactory performance for flow rates ranging between $45 \mathrm{mg} / \mathrm{s}$ to $33 \mathrm{mg} / \mathrm{s}$; however, at a flow rate of $30 \mathrm{mg} / \mathrm{s}$ the arc often did not pull out of low-mode for long durations after ignition. Figure 6 shows data from strip chart recordings of arc current, arc voltage, and pressure for representative starts at $30 \mathrm{mg} / \mathrm{s}$ obtained using the pressure-pulse technique and the soft-start technique. ${ }^{7}$ With the soft-start technique, after $20 \mathrm{~s}$ the arc voltage was low, hovering near $60 \mathrm{~V}$. Using the pressure pulse caused the voltage to approach its steady-state value of $100 \mathrm{~V}$ within fractions of a second.

The pressure shown in the figure is the propellant feed pressure upstream of the injector, which has been found to correspond well with the pressure in the converging section of the nozzle. ${ }^{11}$ For the soft-start technique the pressure increased by a factor of two as the arcjet reached thermal equilibrium over the $20 \mathrm{~s}$ time period shown in the figure. The pressure trace is quite different for the pressure-pulse technique. In the pressure-pulse technique, a monotonic decrease in pressure before ignition is noted. At that time the gas in the accumulator had been released, and the high voltage pulse train had been initiated; however, the arc impedance due to the high pressure exceeded the operating limit of the PPU. Once the pressure reached the upper limit, as established by the PPU parameters, the arc ignited. As shown in Figure 6a, that pressure is a factor of two greater than the pressure established by cold propellant flow shown in Figure 6b. That higher pressure temporarily increased the flow rate through the nozzle, increasing the drag on the arc, and pushing it through the constrictor in less time. With the pressurepulse technique, not only did the voltage approach its steady-state value within fractions of a second after ignition, but the 
pressure was also near the steady-state value immediately after start-up.

Figure 7 shows photomicrographs taken by a scanning electron microscope (SEM) of the Thruster B nozzle before operation and after both 500 and 600 starts. Due to the vortex in the flow, the arc forms helical tracks in the converging side of the nozzle as it is blown through the constrictor. If the arc remains in low-mode too long, it cuts deep grooves in the nozzle. Those grooves become preferential attachment points for successive starts, resulting in a condition which leads to extensive life-limiting damage. If the arc is blown through the constrictor quickly, the only effect of starting on the anode is a slight melting of the material on the surface. Successive starts then follow random paths, giving the appearance shown in Figure 7c. The nozzle was examined after each block of 100 starts and the arc tracks, which extended several millimeters upstream of the constrictor, were numerous and were evenly distributed across the anode surface, signifying random arc paths. Figure $7 \mathrm{c}$ shows that the nozzle after 500 starts was still in excellent condition. A small amount of erosion was noted on the left-hand side of the constrictor; however, the erosion had not penetrated through to the diverging side, and the throat retained its circular shape.

For a direct comparision, photos of the nozzle used for the soft-start test in Ref. 7 are provided in Figure 8 . These photos show that the soft-start technique resulted in significantly greater erosion in the converging section than the pressure-pulse technique. Not only was the converging section erosion increased, but also the circular throat geometry had become distorted. At the end of 500 starts the pressure-pulse technique had clearly demonstrated an advantage over using only PPU current-control techniques.

Because the nozzle was still in very good condition after 500 starts, it was decided to conduct an additional 100 starts at a decreased flow rate to $25 \mathrm{mg} / \mathrm{s}$. Figures $7 \mathrm{e}$ and $7 \mathrm{f}$ provide SEM photomicrographs of the nozzle after the additional testing. The additional 100 starts caused a small amount of erosion on the right side of the constrictor; however, the general condition of the nozzle was good and further tests could have been accommodated.

\section{CONCLUDING REMARKS}

Advanced hydrazine arcjet systems have demonstrated that operation at specific impulse levels above $600 \mathrm{~s}$ is quite possible. To obtain these high performance levels, the propellant mass flow rate is decreased to levels well below those used in state-ofart systems. The reduced flow rates have caused starting reliability to become a significant issue.

A new technique which uses a pressure pulse to force the arc quickly into its steady-state condition has been developed and demonstrated. Starting characteristics obtained with the technique compared favorably with those obtained using conventional starting methods across a wide range of flow rates and, in fact, permitted starting at flow rates below those at which conventional techniques failed. A multistart test was successfully carried out, demonstrating the technique under conditions similar to those anticipated in high performance systems for operational spacecraft. The test consisted of 600 starts conducted in blocks of 100 starts each at flow rates ranging from 45 $\mathrm{mg} / \mathrm{s}$ to $25 \mathrm{mg} / \mathrm{s}$. Post-test examination of the anode showed that nozzle damage was minimal, suggesting that the technique could be beneficial even under more stressful conditions.

\section{REFERENCES}

1. Curran, F.M. and Haag, T.W., "Extended Life and Performance Test of a Low-Power Arcjet," J. of Spacecraft and Rockets, Vol. 29, No. 4, July-Aug. 1992, pp. 444-452.

2. Smith, R.D., et al., "Flight Qualification of a $1.8 \mathrm{~kW}$ 
Hydrazine Arcjet System," IEPC93-007, Proceedings of the 23rd International Electric Propulsion Conference, September 1993.

3. Lichon, P.G. and Sankovic, J.M., "Development and Demonstration of a 600 s Mission Average Arcjet," IEPC-93-087, Proceedings of the 23rd International Electric Propulsion Conference, September 1993.

4. Gruber, R.P., "Power Electronics for a 1-Kilowatt Arcjet Thruster," AIAA 86-1507 (also NASA TM 87340), June 1986.

5. Sarmiento, C.J. and Gruber, R.P., "Low Power Arcjet Thruster Pulse Ignition," AIAA 87-1951 (also NASA TM 100123), July 1987.

6. Pencil, E.J., et al., "Dependence of Hydrogen Arcjet Operation on Electrode Geometry," AIAA 923530 (also NASA TM 105855), July 1992.

7. Hamley, J.A. and Sankovic, J.M., "A Soft-Start Circuit for Arcjet Ignition," AIAA 93-2396 (also NASA TM 106287), June 1993.

8. Curran, F.M. and Haag, T.W., "Arcjet Component Conditions Through a Multistart Test," AIAA 87-1060 (also NASA TM 89857), May 1987.

9. Haag, T.W., "Recent Testing of 30 kW Hydrogen Arcjet Thrusters," AIAA 93-1902 (also NASA TM 106214), July 1993.

10. Curran, F.M. and Manzella, D.H., "The Effect of Electrode Configuration on Arcjet Performance," NASA TM 102346, July 1989.

11. Talley, K. and Elrod, W., "Static Pressure Measurements of the
NASA-Lewis $1.2 \mathrm{~kW}$ Arcjet," AIAA 92-3111, July 1992. 


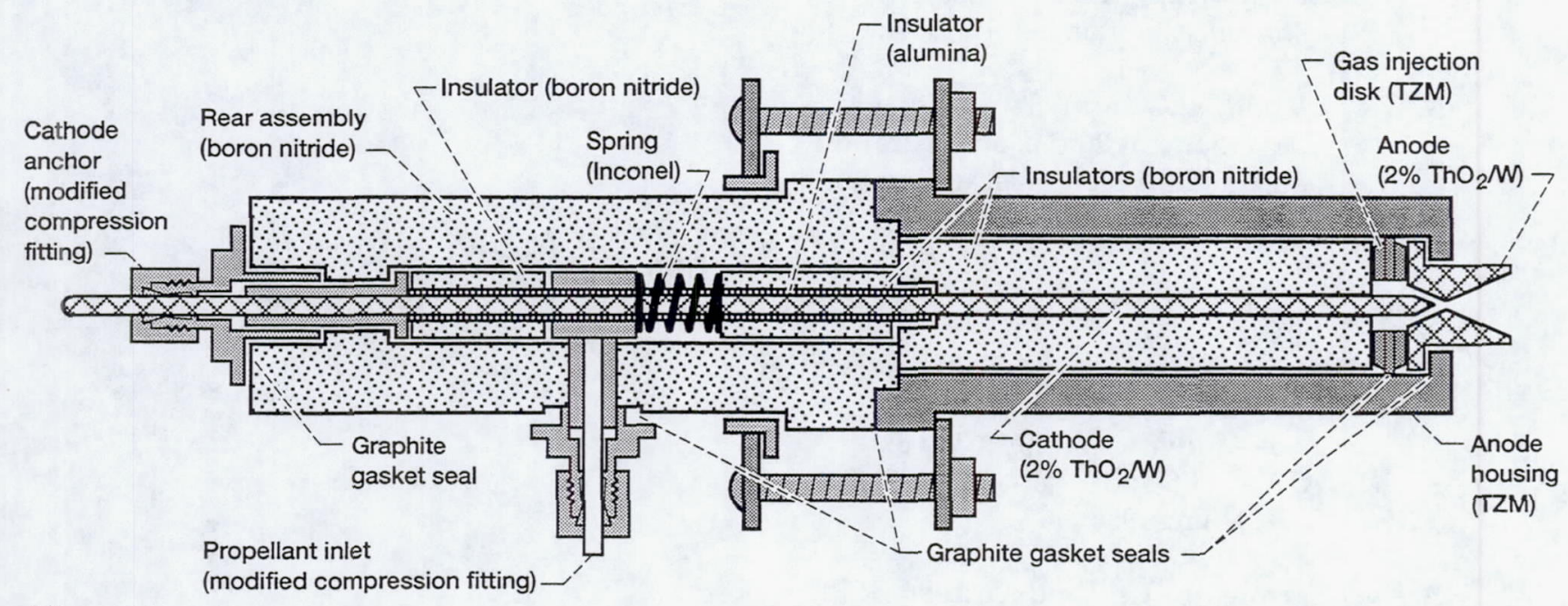

(a)
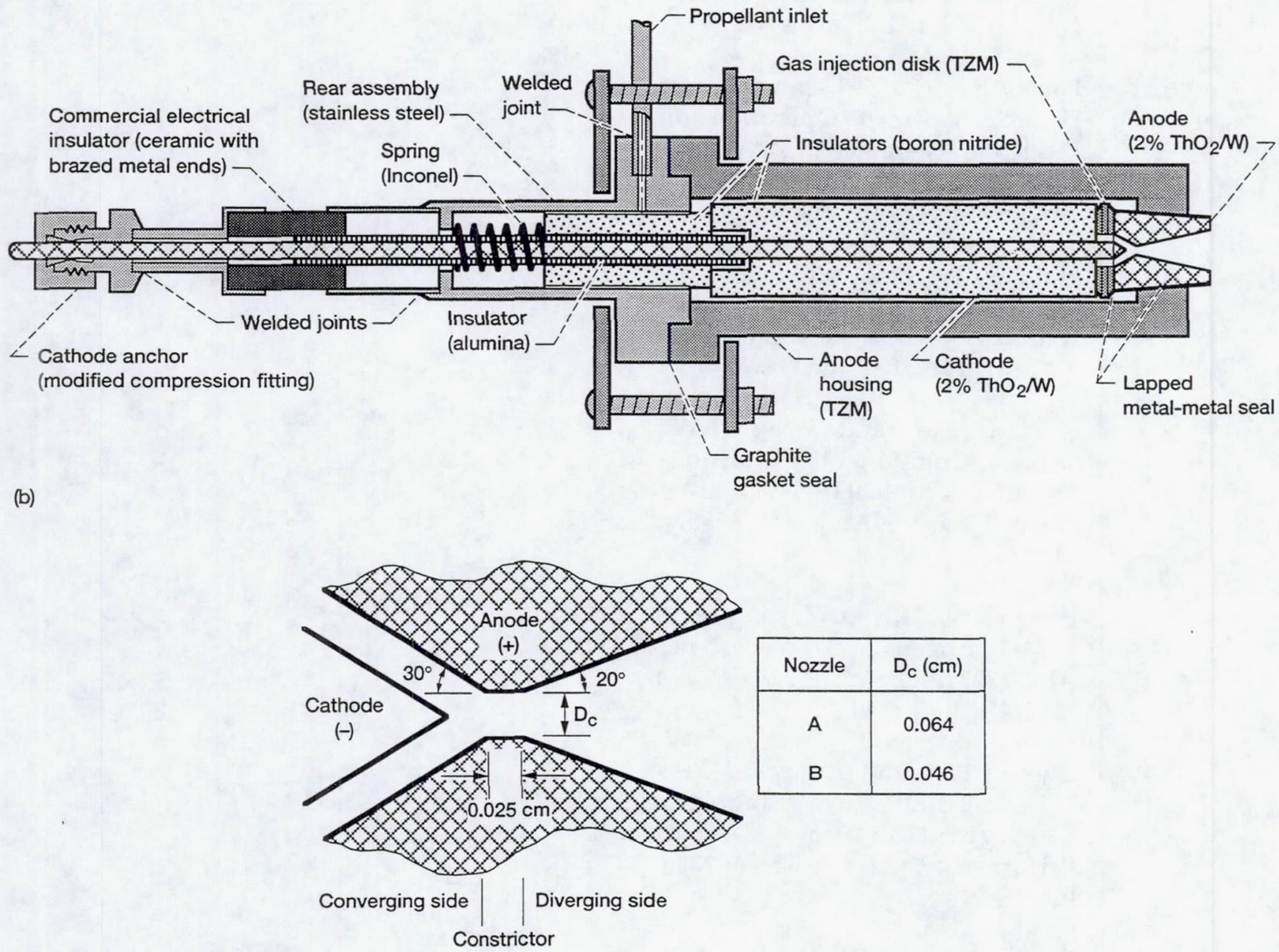

(c)

Figure 1.-Schematics of arcjet thrusters tested. (a) Arcjet thruster design A. (b) Arcjet thruster design B. (c) Electrode geometry. 


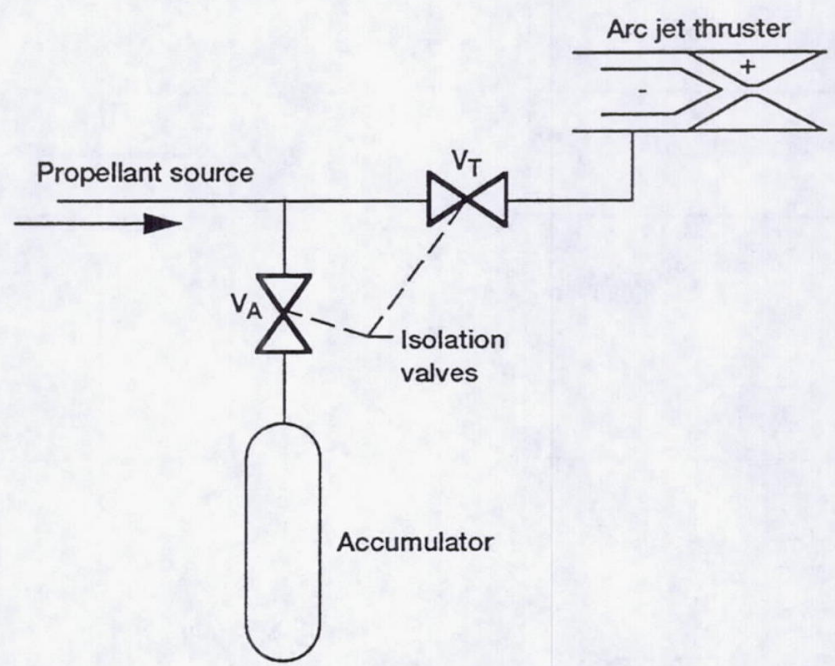

Figure 2.-Schematic of pressure-pulse generation apparatus.

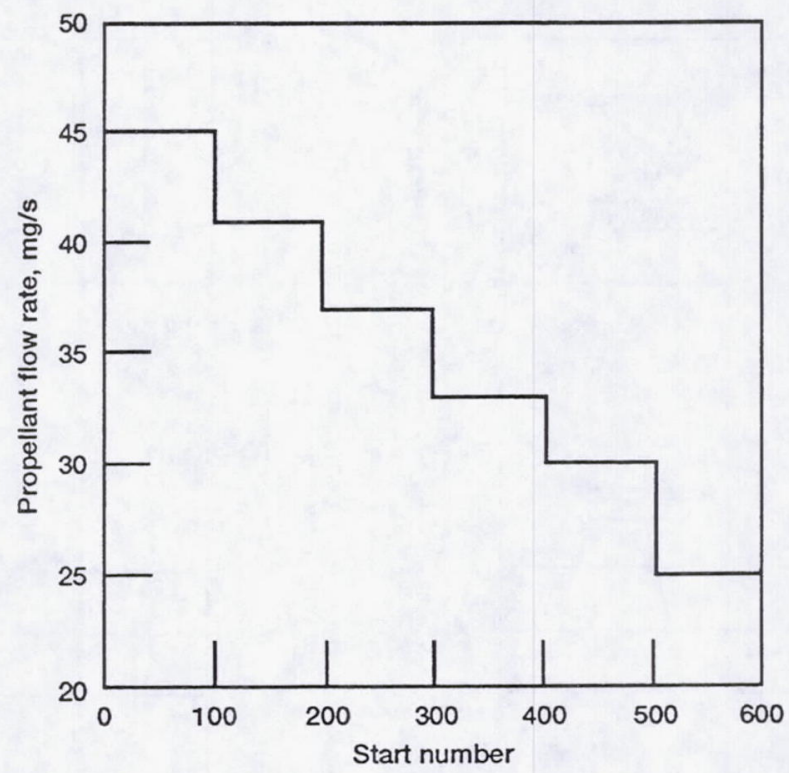

Figure 3.-Range of propellant flow rates used in multistart test. 

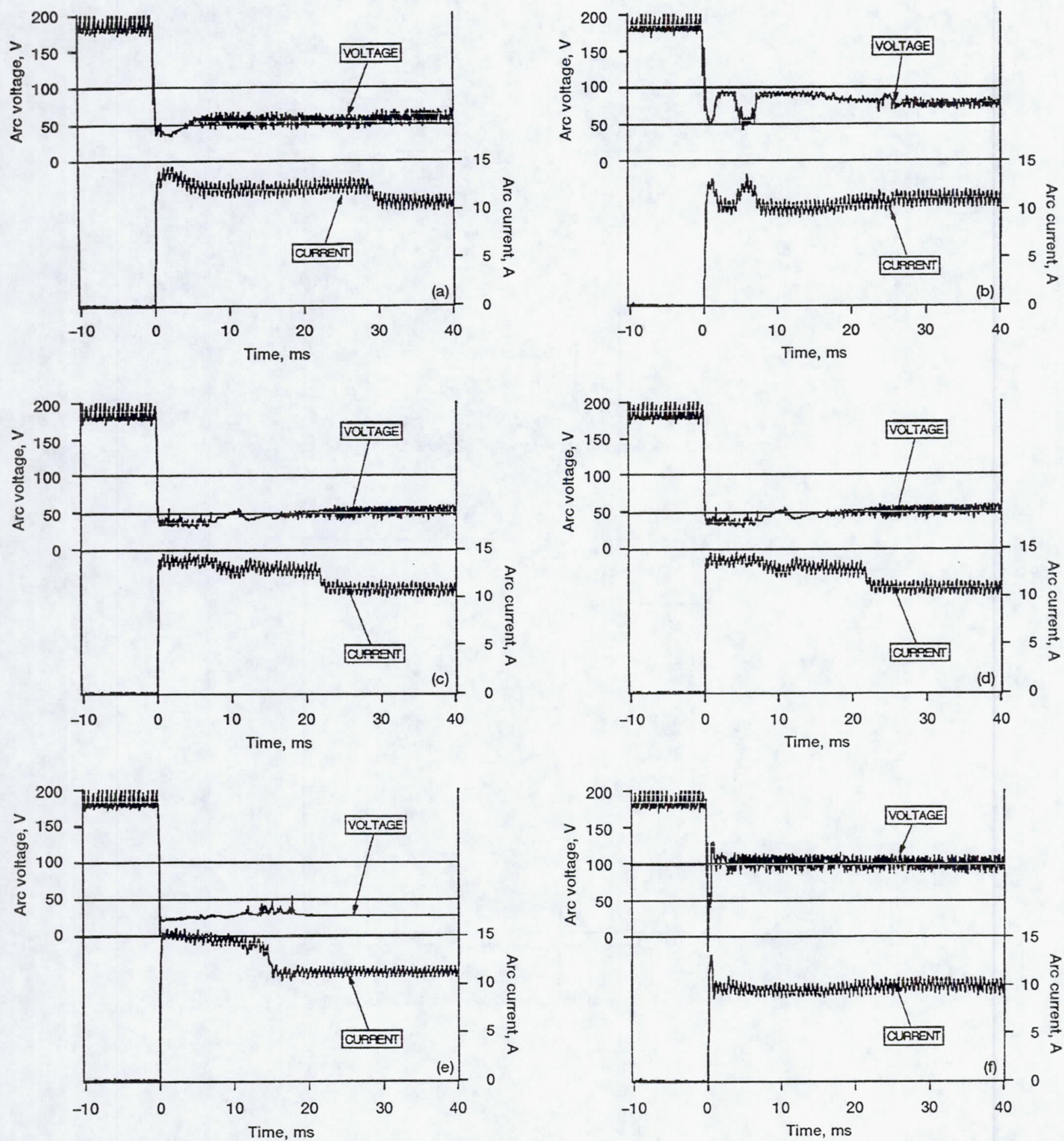

Figure 4.-Oscilloscope traces of voltage and current comparing state-of-art starting method with pressure pulse technique at various flow rates. (a) State-of-art; $45 \mathrm{mg} / \mathrm{s}$. (b) Pressure-pulse; $45 \mathrm{mg} / \mathrm{s}$. (c) State-of-art; $33 \mathrm{mg} / \mathrm{s}$. (d) Pressure-pulse; $33 \mathrm{mg} / \mathrm{s}$. (e) State-of-art; $21 \mathrm{mg} / \mathrm{s}$.

(f) Pressure-pulse; $21 \mathrm{mg} / \mathrm{s}$. 

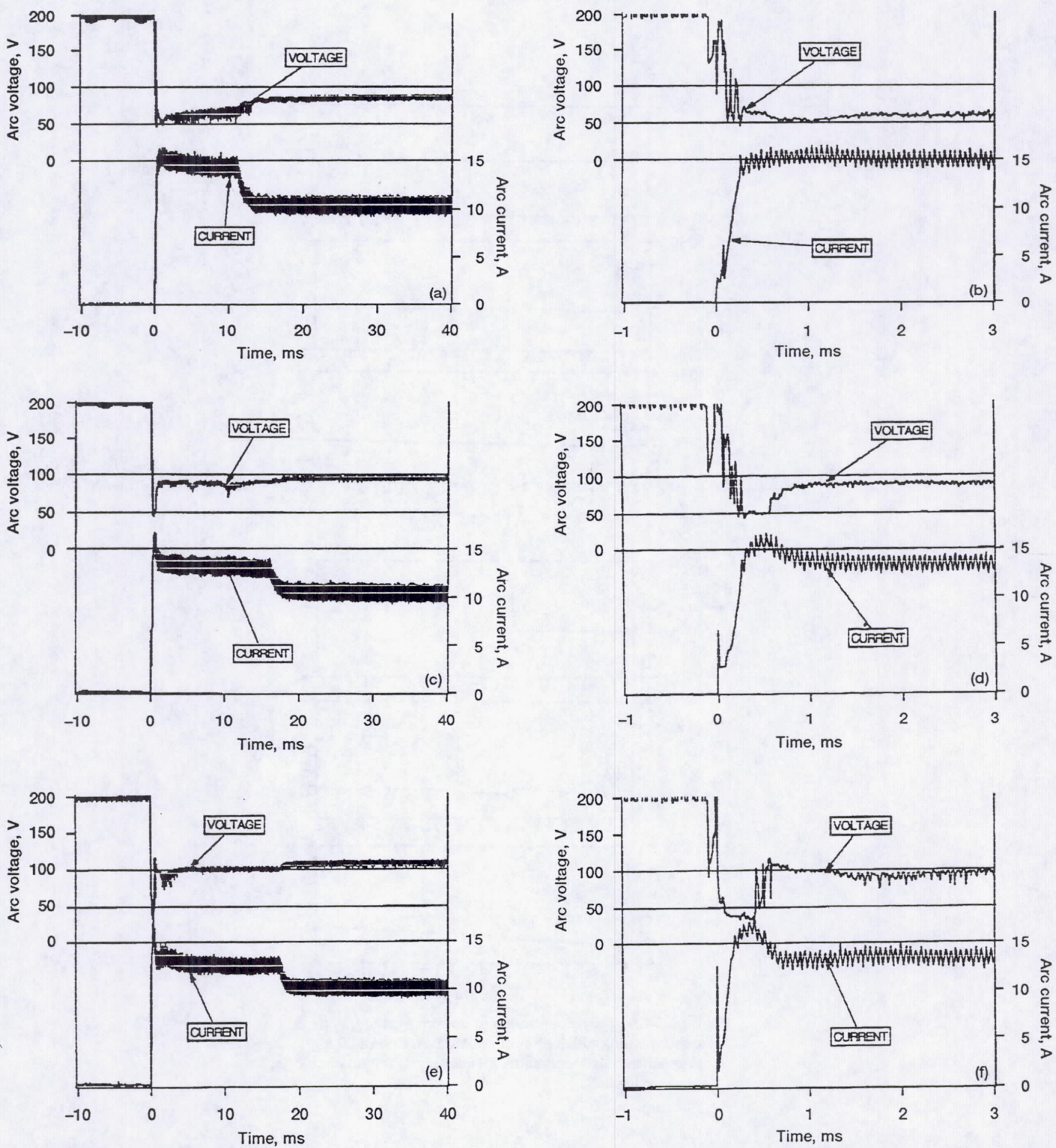

Figure 5.-Typical oscilloscope traces of voltage and current obtained at various flow rates during multistart test utilizing pressure-pulse technique. (a) $45 \mathrm{mg} / \mathrm{s} ; 40 \mathrm{~ms}$ after ignition. (b) $45 \mathrm{mg} / \mathrm{s} ; 3 \mathrm{~ms}$ after ignition. (c) $33 \mathrm{mg} / \mathrm{s} ; 40 \mathrm{~ms}$ after ignition. (d) $33 \mathrm{mg} / \mathrm{s} ; 3 \mathrm{~ms}$ after ignition. (e) $25 \mathrm{mg} / \mathrm{s} ; 40 \mathrm{~ms}$ after ignition. (f) $25 \mathrm{mg} / \mathrm{s} ; 3 \mathrm{~ms}$ after ignition. 

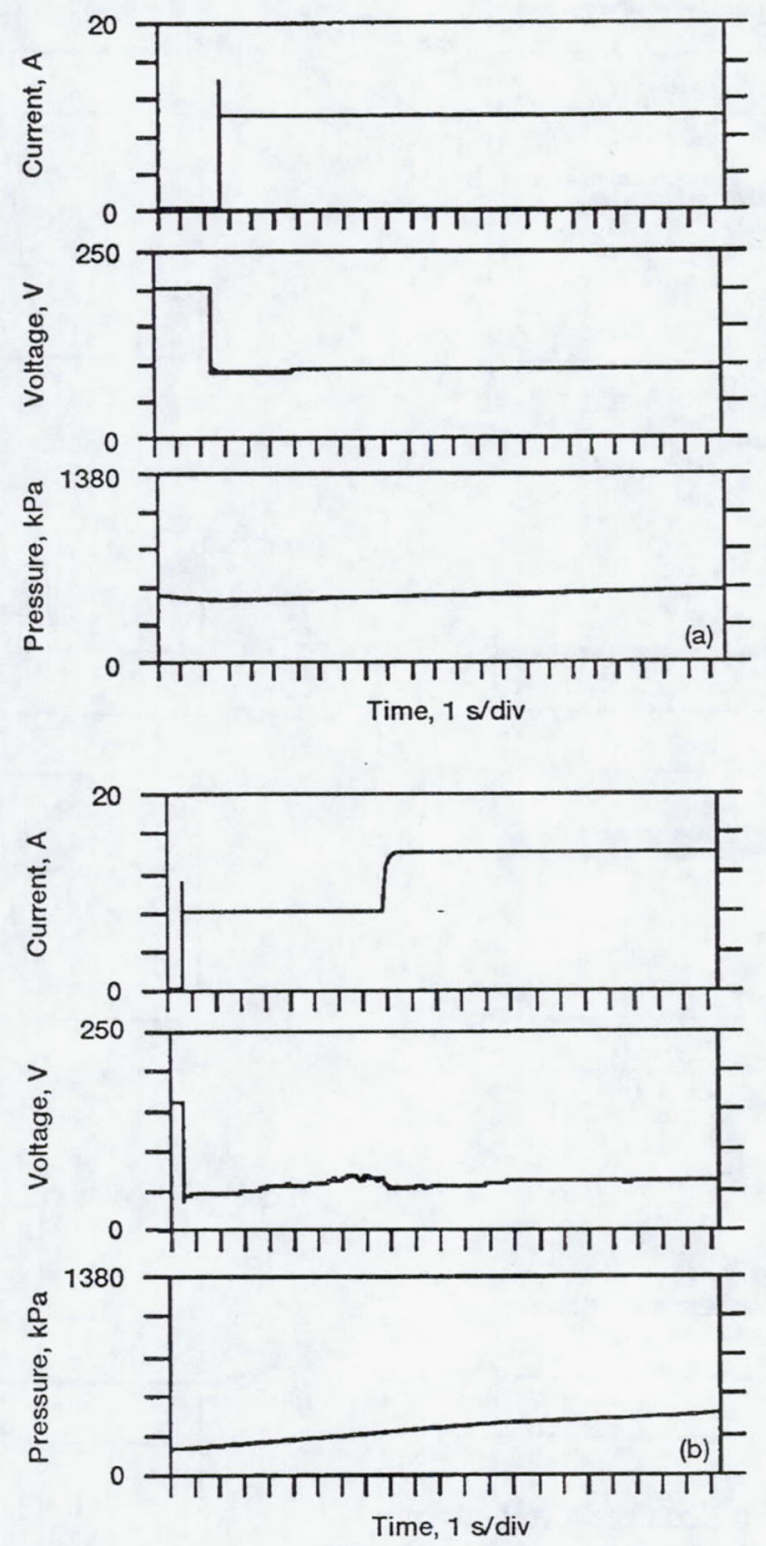

Figure 6.-Chart recorder traces of current, voltage, and pressure after ignition at a propellant flow rate of $30 \mathrm{mg} / \mathrm{s}$. (a) Pressure-pulse technique. (b) Soft-start ignition circuit technique [Ref. 7]. 

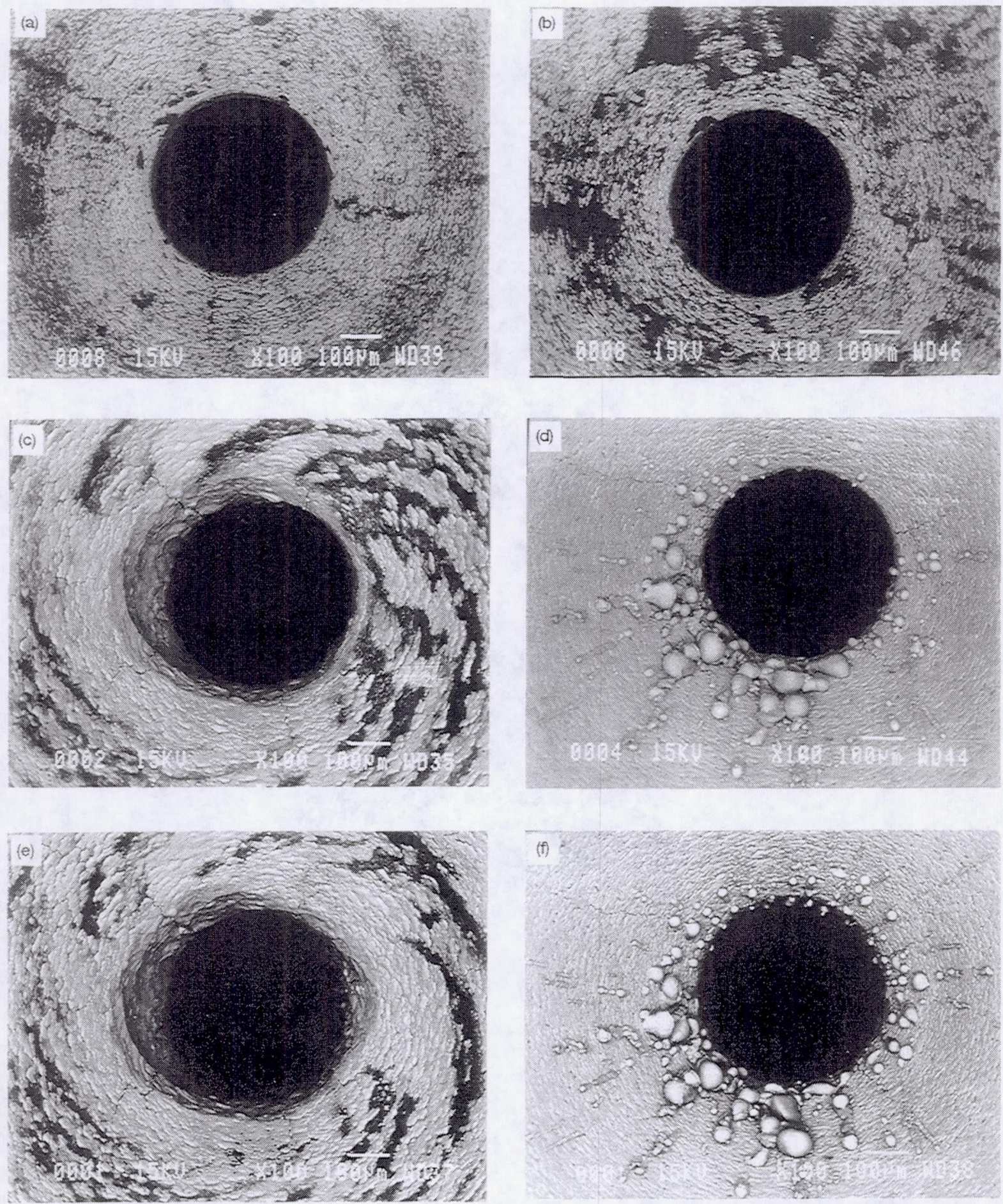

Figure 7.-Photomicrographs of nozzle. (a) Converging side, pre-test. (b) Diverging side, pre-test. (c) Converging side, 500 starts. (d) Diverging side, 500 starts. (e) Converging side, 600 starts. (f) Diverging side, 600 starts. 

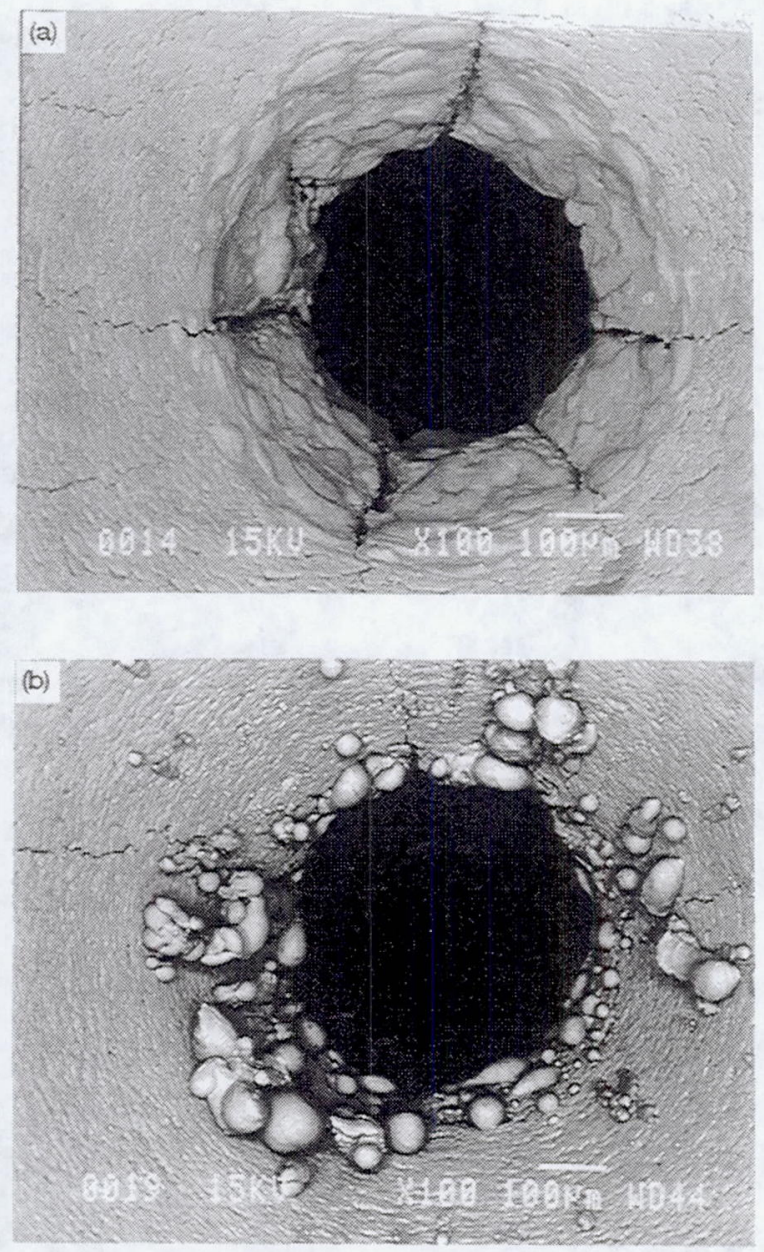

Figure 8.-Photomicrographs of anode from Ref. 7 after 500 starts utilizing soft-start ignition circuit. (a) Converging side. (b) Diverging side. 
Public reporting burden for this collection of information is estimated to average 1 hour per response, including the time for reviewing instructions, searching existing data sources, gathering and maintaining the data needed, and completing and reviewing the collection of information. Send comments regarding this burden estimate or any other aspect of this collection of information, including suggestions for reducing this burden, to Washington Headquarters Services. Directorate for Information Operations and Reports, 1215 Jeffers Davis Highway, Suite 1204, Arlington, VA 22202-4302, and to the Office of Management and Budget, Paperwork Reduction Project (0704-0188), Washington, DC 20503.
1. AGENCY USE ONLY (Leave blank)
2. REPORT DATE
September 1994
3. REPORT TYPE AND DATES COVERED
Technical Memorandum

4. TITLE AND SUBTITLE

5. FUNDING NUMBERS

A Low-Erosion Starting Technique for High-Performance Arcjets

6. AUTHOR(S)

WU-506-42-31

John M. Sankovic and Francis M. Curran

7. PERFORMING ORGANIZATION NAME(S) AND ADDRESS(ES)

8. PERFORMING ORGANIZATION REPORT NUMBER

National Aeronautics and Space Administration

Lewis Research Center

Cleveland, Ohio 44135-3191

E-8921

9. SPONSORING/MONITORING AGENCY NAME(S) AND ADDRESS(ES)

10. SPONSORING/MONITORING AGENCY REPORT NUMBER

National Aeronautics and Space Administration

Washington, D.C. 20546-0001

NASA TM-106627

11. SUPPLEMENTARY NOTES

Prepared for the 30th Joint Propulsion Conference cosponsored by AIAA, ASME, SAE, and ASEE, Indianapolis, Indiana, June 27-29, 1994. Responsible person, John M. Sankovic, organization code 5330, (216) 977-7429.

12a. DISTRIBUTION/AVAILABILITY STATEMENT

12b. DISTRIBUTION CODE

Unclassified - Unlimited

Subject Category 20

\section{ABSTRACT (Maximum 200 words)}

The NASA arcjet program is currently sponsoring development of high specific impulse thrusters for next generation geosynchronous communications satellites ( $2 \mathrm{~kW}$-class) and low-power arcjets for power limited spacecraft ( 0.5 kWclass). Performance goals in both of these efforts will require up to 1000 starts at propellant mass flow rates significantly below those used in state-of-the-art arcjet thruster systems (i.e., high specific power levels). Reductions in mass flow rate can lead to damaging modes of operation, particularly at thruster ignition. During the starting sequence, the gas dynamic force due to low propellant flow is often insufficient to rapidly push the arc anode attachment to its steady-state position in the diverging section of the nozzle. This paper describes the development and demonstration of a technique which provides for non-damaging starts at low steady-state flow rates. The technique employs a brief propellant pressure pulse at ignition to increase gas dynamic forces during the critical ignition/transition phase of operation. Starting characteristics obtained using both pressure-pulsed and conventional starting techniques were compared across a wide range of propellant flow rates. The pressure-pulsed starting technique provided reliable starts at mass flow rates down to $21 \mathrm{mg} / \mathrm{s}$, typically required for $700 \mathrm{~s}$ specific impulse level operation of $2 \mathrm{~kW}$ thrusters. Following the comparison, a $600 \mathrm{start}$ test was performed across a wide flow rate range. Post-test inspection showed minimal erosion of critical arcjet anode/nozzle surfaces.

\section{SUBJECT TERMS}

Electric propulsion; Arcjet thrusters; Electrodes; Ignition

17. SECURITY CLASSIFICATION OF REPORT Unclassified

18. SECURITY CLASSIFICATION
OF THIS PAGE
Unclassified

Unclassified
19. SECURITY CLASSIFICATION OF ABSTRACT Unclassified 